\title{
Hemoglobin level at initiation of darbepoetin alfa: impact on need for transfusion and associated costs in chemotherapy-induced anemia treatment in Europe
}

\author{
Melike Deger • Wolfgang Eisterer • Lucie Kutikova • \\ Sam Salek
}

Received: 8 February 2012 / Accepted: 25 June 2012 /Published online: 24 July 2012

(C) The Author(s) 2012. This article is published with open access at Springerlink.com

\begin{abstract}
Purpose Erythropoiesis-stimulating agents can reduce red blood cell transfusion rates in patients developing anemia while receiving chemotherapy. We investigated potential cost savings from reduced transfusion rates in patients starting darbepoetin alfa (DA) at higher versus lower hemoglobin $\mathrm{Hb}$ levels.

Methods Two systematic literature reviews were performed: transfusion outcomes in patients receiving DA stratified by baseline $\mathrm{Hb}$ level and costs of transfusion in Europe. Potential cost savings were calculated by multiplying the difference in transfusion rates between $\mathrm{Hb}$ levels by the midpoint of transfusion costs.

Results Despite differences in baseline characteristics, treatment duration and analysis technique, the clinical studies $(n=8)$ showed that fewer transfusions were required when $\mathrm{DA}$ was initiated at higher versus lower $\mathrm{Hb}$ levels. The
\end{abstract}

\author{
M. Deger \\ Welsh School of Pharmacy, Cardiff University, \\ Redwood Building, King Edward VII Avenue, \\ Cardiff CF10 3NB, UK \\ M. Deger • L. Kutikova \\ Amgen Europe GmbH, \\ Dammstrasse 23, \\ 6300 Zug, Switzerland \\ W. Eisterer \\ Department for Internal Medicine I, Medical University Innsbruck, \\ Anichstrasse 35, \\ 6020 Innsbruck, Austria \\ S. Salek $(\varangle)$ \\ Centre for Socioeconomic Research, Welsh School of Pharmacy, \\ Cardiff University, \\ Redwood Building, King Edward VII Avenue, \\ Cardiff CF10 3NB, UK \\ e-mail: salekss@cardiff.ac.uk
}

economic studies $(n=9)$ showed that 1 unit of transfusion ranged from $€ 130$ to $€ 537$ (2010-adjusted values). Cost savings from initiating DA at higher versus lower $\mathrm{Hb}$ levels were $€ 503-2,226$ ( 2 units transfused) and $€ 880-3,895$ (3.5 units) per ten patients.

Conclusions Transfusion incidence increases with DA initiation at lower $\mathrm{Hb}$ levels. Potential cost savings depend on the number of units transfused and cost items included. DA initiation according to guidelines can reduce transfusions and potentially reduce transfusion-associated costs.

Keywords Costs $\cdot$ Darbepoetin alfa $\cdot$ Erythropoiesisstimulating agents $\cdot$ Hemoglobin $\cdot$ Transfusion

\section{Introduction}

Chemotherapy is a frequent cause of anemia in patients with cancer [1]. In this population, anemia increases the risk of death [2], and is also associated with impaired quality of life $[3,4]$. Until the early 1980 s, red blood cell (RBC) transfusions were the primary treatment for chemotherapyinduced anemia [5]. This changed in 1993 when the use of erythropoiesis-stimulating agents (ESAs) was approved by the US Food and Drug Administration for the treatment of anemia in patients with cancer. Approval of ESAs in Europe by the European Medicines Agency followed in 2001. Notably, ESA treatment of chemotherapy-induced anemia can reduce the requirements for $\mathrm{RBC}$ transfusions [6], which are associated with various risks including enhanced tumor growth, transmission of infectious diseases, and adverse reactions [1].

The goal of the treatment is improving fatigue symptoms by correcting anemia. According to current guidelines from the European Organisation for Research and Treatment of 
Cancer, ESA treatment should be initiated at a hemoglobin $(\mathrm{Hb})$ level of $9-11 \mathrm{~g} / \mathrm{dl}$ in patients experiencing anemiarelated symptoms while receiving systemic chemotherapy [6]. The European Society for Medical Oncology (ESMO) acknowledges the importance of anemia in cancer, through the negative impact upon the quality of life and as a negative prognosis factor regarding general survival [7]. ESMO recommends ESA use in the treatment of the symptomatic anemia induced by chemotherapy of adult patients with nonmyeloid malignancies with $\mathrm{Hb}$ values $\leq 10 \mathrm{~g} / \mathrm{dl}$. The goal of the treatment is improving the fatigue symptoms by correcting anemia. ASCO/ASH recommends use of ESA when $\mathrm{Hb}$ levels are $\leq 10 \mathrm{~g} / \mathrm{dL}$ while considering other clinical circumstances [8]. Similarly, the European Summaries of Product Characteristics for ESAs state that treatment should be initiated when the $\mathrm{Hb}$ level falls to $\leq 10 \mathrm{~g} / \mathrm{dl}$ [9-11]. In contrast, based on recent RBC transfusion guidelines [12], the recommended hemoglobin trigger for transfusion should be $7 \mathrm{~g} / \mathrm{dL}$ in stable, non-bleeding patients.

Importantly, the $\mathrm{Hb}$ level at the time of ESA initiation may affect clinical outcomes, including RBC transfusion rates. For example, a retrospective analysis of a darbepoetin alfa (DA) study showed that the incidence of RBC transfusion was $31 \%$ when treatment was initiated at $\mathrm{Hb}$ levels $<10 \mathrm{~g} / \mathrm{dl}$ compared with $15 \%$ when treatment was initiated at $\mathrm{Hb}$ levels $>10 \mathrm{~g} / \mathrm{dl}$ [13]. This in turn may affect the costs of treating chemotherapy-induced anemia.

The aims of the present retrospective study were to investigate the impact of $\mathrm{Hb}$ level at the start of ESA treatment on the rate of RBC transfusion and to identify the potential cost-saving benefit of a reduction in transfusion rates, based on a systematic review of the literature. The present study focuses on DA, an injectable, long-acting erythropoietin with increased erythropoietinstimulating activity relative to epoetin [14]. DA can be dosed as infrequently as once every 3 weeks, which allows treatment to be synchronized with many chemotherapy schedules [15].

\section{Design and methods}

Systematic literature review of relevant clinical studies

A systematic literature review was performed to identify articles that reported RBC transfusion rates stratified by $\mathrm{Hb}$ level at the time of DA initiation in patients with chemotherapy-induced anemia. To capture studies that would be in line with the most recent treatment guidelines [6], a search was conducted using the PubMed database for studies published between January 2006 and November 2010. Iterative searches were also conducted of several conference abstract databases [American Society for Clinical
Oncology, American Society for Hematology, European Society for Medical Oncology (ESMO), ESMO/European Cancer Organisation and European Haematology Association joint congress] for relevant abstracts presented between 2006 and 2010. The search terms were ("darbepoetin alfa" or "darbepoetin alpha") and ("chemotherapy-induced anemia," "chemotherapy-induced anemia," or "CIA"). All articles that reported RBC transfusion rates stratified by $\mathrm{Hb}$ level at DA initiation in patients with chemotherapyinduced anemia were included, regardless of their study designs. Risk differences in RBC transfusion rates at different $\mathrm{Hb}$ stratification levels were calculated for the retrieved studies.

The summary measure to be identified by the systematic review was the risk difference in transfusion rates when DA was initiated at higher versus lower Hb levels. This was calculated [with $95 \%$ confidence intervals $(\mathrm{CI})$ ] by subtracting the transfusion rate at lower $\mathrm{Hb}$ levels from that at higher levels.

Systematic literature review of economic studies

A second systematic literature review was performed to identify articles that reported the cost of RBC transfusion. Iterative searches were conducted using the PubMed database for studies published between November 2000 and November 2010. The following Medical Subject Heading terms were included: "blood transfusion," "autologous/economics," or "anemia/economics." The reference lists of retrieved studies from this review were scanned to identify additional articles, with no date limitation set for reference list reviewing. All articles that reported costs of RBC transfusion were included, regardless of whether they were retrospective or prospective, and whether transfusion was used in oncology or other settings. To minimize potential bias caused by differences among healthcare systems in different geographic regions, studies reporting transfusion costs in Europe were selected for further calculations.

Extracted data on costs of RBC transfusion for each article were first converted to 2010 values using consumer price index values for the relevant country [16-23]. Resulting cost was adjusted to Euro $(€)$ values by using average 2010 currency exchange rates published by the European Central Bank [24]. Average cost per 1 RBC unit was calculated.

For studies using top-down (macro costing) methodology, unit cost was calculated by dividing the overall cost by the total number of units transfused. In studies using bottom-down (micro costing) methodology, each resource component was identified and a unit cost calculated. The overall cost of transfusion includes costs associated with blood collection and processing, as well as transfusion. 
Fig. 1 Flow diagram of study selection for clinical studies. Asterisk two studies identified by the literature searches as conference abstracts have since been published [22, $30]$ and are included here as full text articles

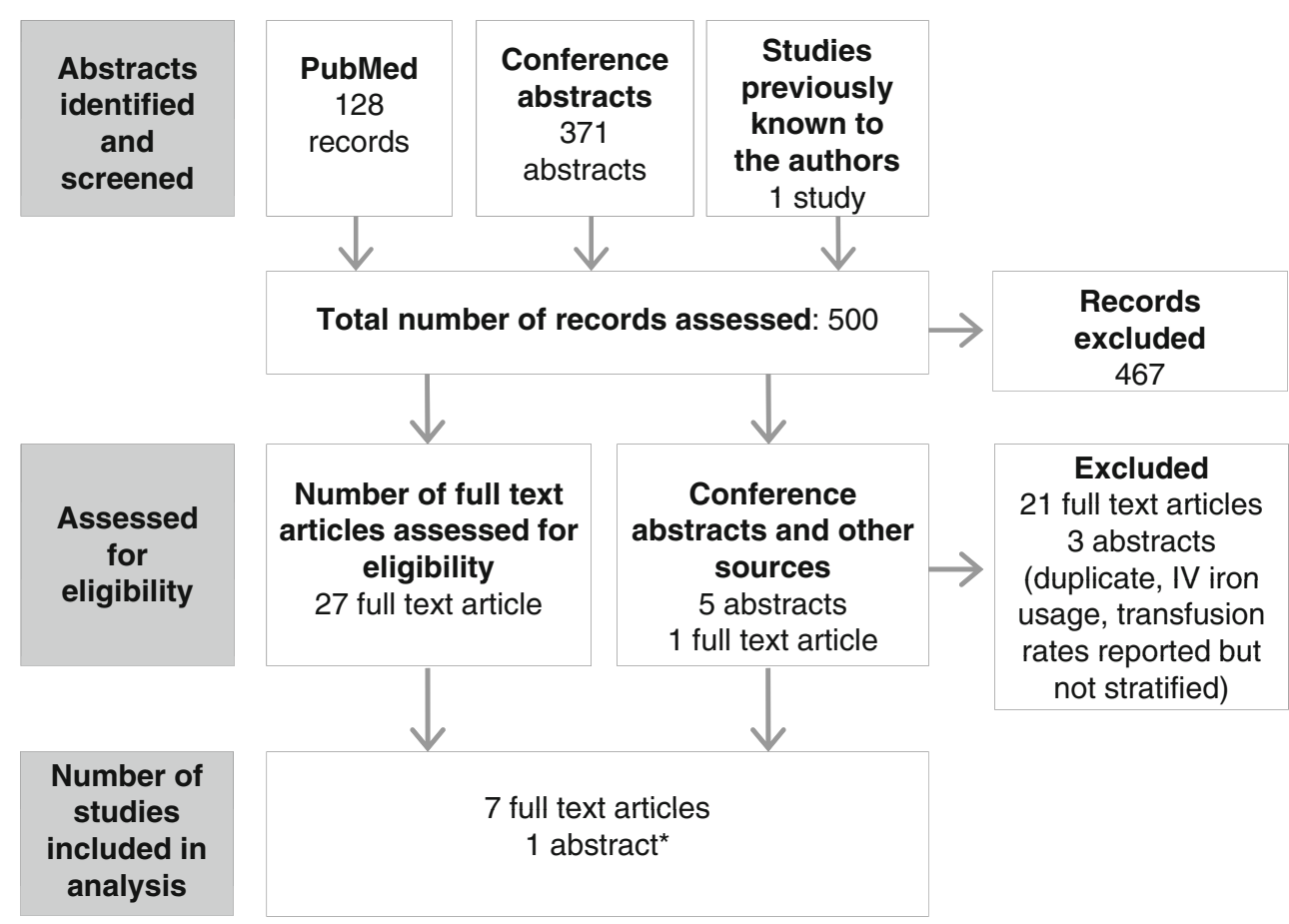

\section{Calculation of cost savings}

To identify cost savings in the treatment of chemotherapyinduced anemia associated with $\mathrm{Hb}$ level at the time of DA initiation, the risk difference in $\mathrm{RBC}$ transfusion rates (based on that identified in the systematic review of clinical studies) was multiplied by the identified average of RBC transfusion cost in Europe (based on the systematic review of economic studies). Among the retrieved clinical studies, only one reported the actual number of units transfused (3.5 units) [25], while 2 units have been reported as an average number of units typically transfused [26, 27]. Cost savings were, therefore, calculated based on transfusion of 2 and 3.5 units of RBC.

\section{Results}

Systematic literature review of clinical studies

The initial PubMed and conference abstract searches revealed 500 potentially relevant articles, of which 27 fulltext articles and 4 abstracts were assessed further for eligibility. Of these, eight publications were identified for inclusion in the clinical literature review, including seven fulltext articles [25, 28-33] and one conference abstract (Fig. 1; Table 1) [34]. Five publications were based on data from clinical trials [29-31, 33, 34] and two reported results of observational studies $[25,31]$, with one pooled analysis of individual patient-level data from several clinical trials [32].
The eight independent studies used six different stratification levels for $\mathrm{Hb}$.

Impact of hemoglobin level at DA initiation on RBC transfusion rate Despite the differences in baseline patient characteristics, dose and regimen of DA, length of study, and analytical techniques, all eight studies demonstrated a reduced need for RBC transfusion when DA was initiated at higher versus lower $\mathrm{Hb}$ levels.

Three studies stratified $\mathrm{Hb}$ at the $<10$ versus $\geq 10 \mathrm{~g} / \mathrm{dl}$ level. In two, DA was administered at $300 \mu \mathrm{g}$ every 3 weeks (Q3W) for 13 weeks [29] or 16 weeks [34], and transfusion rates were reported between weeks 5 and 16 . In the third study, DA $200 \mu \mathrm{g}$ was given Q2W for 24 weeks, and transfusion rates were reported for months 1 and 6 [25]. The risk difference in transfusion rates ranged between $16 \%$ (95\% CI, 11-21\%) and $19 \%$ (95\% CI, 10-28\%).

One study [30] stratified $\mathrm{Hb}$ at the $\leq 10$ versus $10.5-12 \mathrm{~g} / \mathrm{dl}$ level. ${ }^{1}$ DA $300 \mu \mathrm{g}$ was given Q3W for 22 weeks and the transfusion incidence reported as the Kaplan-Meier percentage $(\mathrm{K}-\mathrm{M} \%)$ for weeks $1-13$. The difference in risk of transfusion was $17 \%$ (95\% CI, 4-30\%) in favor of the higher $\mathrm{Hb}$ level. Another study stratified $\mathrm{Hb}$ at the $<9$ versus $\geq 9 \mathrm{~g} / \mathrm{dl}$ level [32]. This was a 16-week prospective observational study using DA $150 \mu \mathrm{g}$ weekly with transfusion rates reported for weeks 5-16. The risk difference for transfusion rates was $7 \%$ $(95 \%$ CI, $-5-19 \%)$ in favor of the higher Hb level.

\footnotetext{
${ }^{1}$ Patients received DA immediately $(\mathrm{Hb} \geq 10.5 \mathrm{~g} / \mathrm{dl})$ or waited until $\mathrm{Hb}$ had decreased below $10 \mathrm{~g} / \mathrm{dl}$.
} 


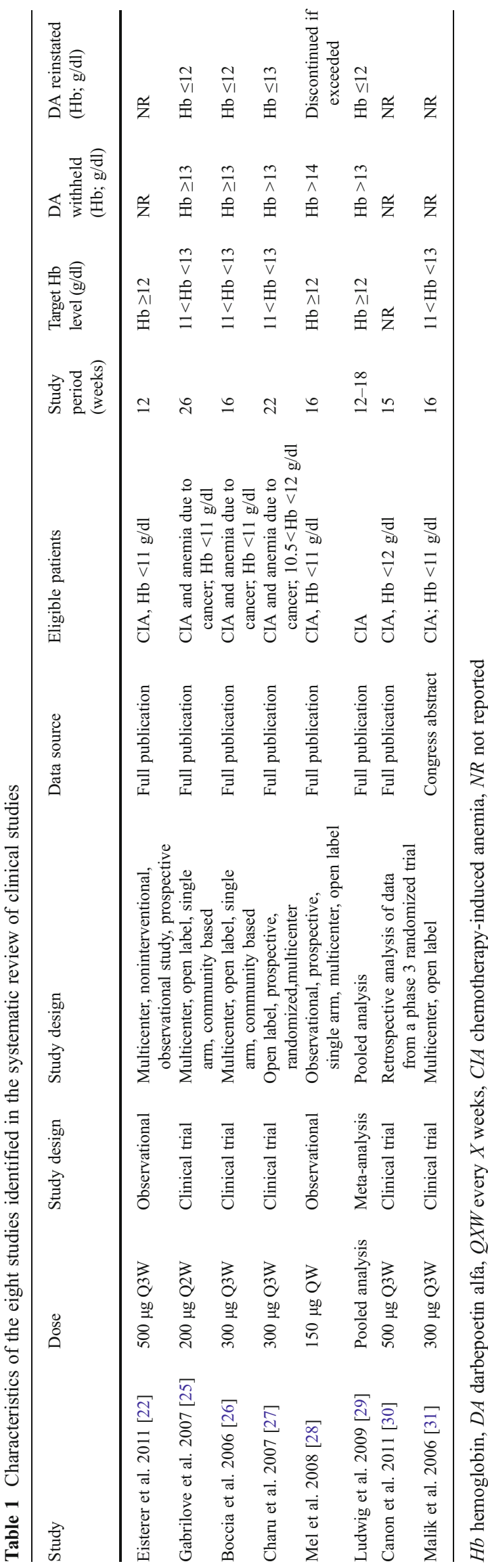

Two studies used three stratification levels for $\mathrm{Hb}$. The first was a 15-week study with DA $500 \mu \mathrm{g}$ Q3W in which $\mathrm{Hb}$ was stratified at $<9,9$ to $<10$, and $\geq 10 \mathrm{~g} / \mathrm{dl}$ [33]. K-M $\%$ transfusion rates were reported for weeks $1-15$ and $5-15$. The risk differences for weeks $1-15$ were $27 \%$ (95\% CI, 16-38\%) for intermediate versus low $\mathrm{Hb}$ and $16 \%$ (95\% CI, 9-23\%) for higher versus intermediate $\mathrm{Hb}$, with slightly lower risk differences when weeks 5-15 were analyzed [ $25 \%$ (95\% CI, 14 $36 \%$ ) and $13 \%$ (95\% CI, 6-20\%), respectively]. The second study was an observational study using DA $500 \mu \mathrm{g}$ Q3W, with $\mathrm{Hb}$ stratified at $<9,9-10$, and $>10 \mathrm{~g} / \mathrm{dl}$ [25]. The differences in transfusion risk for weeks $1-12$ were $31 \%(95 \% \mathrm{CI}, 12$ $50 \%)$ for intermediate versus low $\mathrm{Hb}$ and $9 \%(95 \% \mathrm{CI}, 1-$ $17 \%$ ) for higher versus intermediate $\mathrm{Hb}$.

The final study, a pooled analysis of six studies with various DA dosing regimens, used five $\mathrm{Hb}$ stratification levels: $<9,9$ to $<10,10$ to $<11,11$ to $<12$, and $\geq 12 \mathrm{~g} / \mathrm{dl}$ [32]. K-M $\%$ transfusion rates were reported for week 5 to weeks 12-18. Risk differences for the four comparisons were $10 \%(95 \% \mathrm{CI}, 1-19 \%), 12 \%(95 \% \mathrm{CI}$, 5-19\%), $7 \%$ (95\% CI, 1-13\%), and $0 \%$ (95\% CI, -7 to $7 \%$, respectively.

\section{Systematic literature review of economic studies}

The initial PubMed searches revealed 286 potentially relevant articles, of which 4 met the inclusion criteria. The reference lists of these four articles were then analyzed and additional articles identified, giving a total of 21 publications that met the inclusion criteria for the economic literature reviews, of which 8 were European (Fig. 2; Table 2) $[26,27,35-40]$. One more study was identified at a later stage [41]. There were three from the UK, one each from Greece, Norway, Portugal, Spain, and Sweden, and one that included costs from Switzerland and Austria. The studies were conducted between 1998 and 2008, and all reported the actual year of the study and the actual-year costs.

Three studies assessed the cost of transfusion in an oncology setting (one in a general oncology department, one in a hemato-oncology department, and one in hematology and oncology departments), two in a surgery setting, and three in a general hospital setting, and one was a review. The costs reported in our systematic review are all allogeneic transfusion cost. The costs of transfusion were most frequently assessed from the hospitals' perspective (4/9 studies). Societal perspective was the approach in two studies, in which indirect costs such as donor productivity loss, donor transportation costs, and patient transportation costs were also considered. One study took the healthcare provider's perspective, and one took the payer's perspective.

Cost of RBC transfusion The 2010-adjusted cost of 1 unit of $\mathrm{RBC}$ transfusion in Europe ranged from $€ 130$ to $€ 537$ (Table 3), 
Fig. 2 Flow diagram of study selection for economic studies

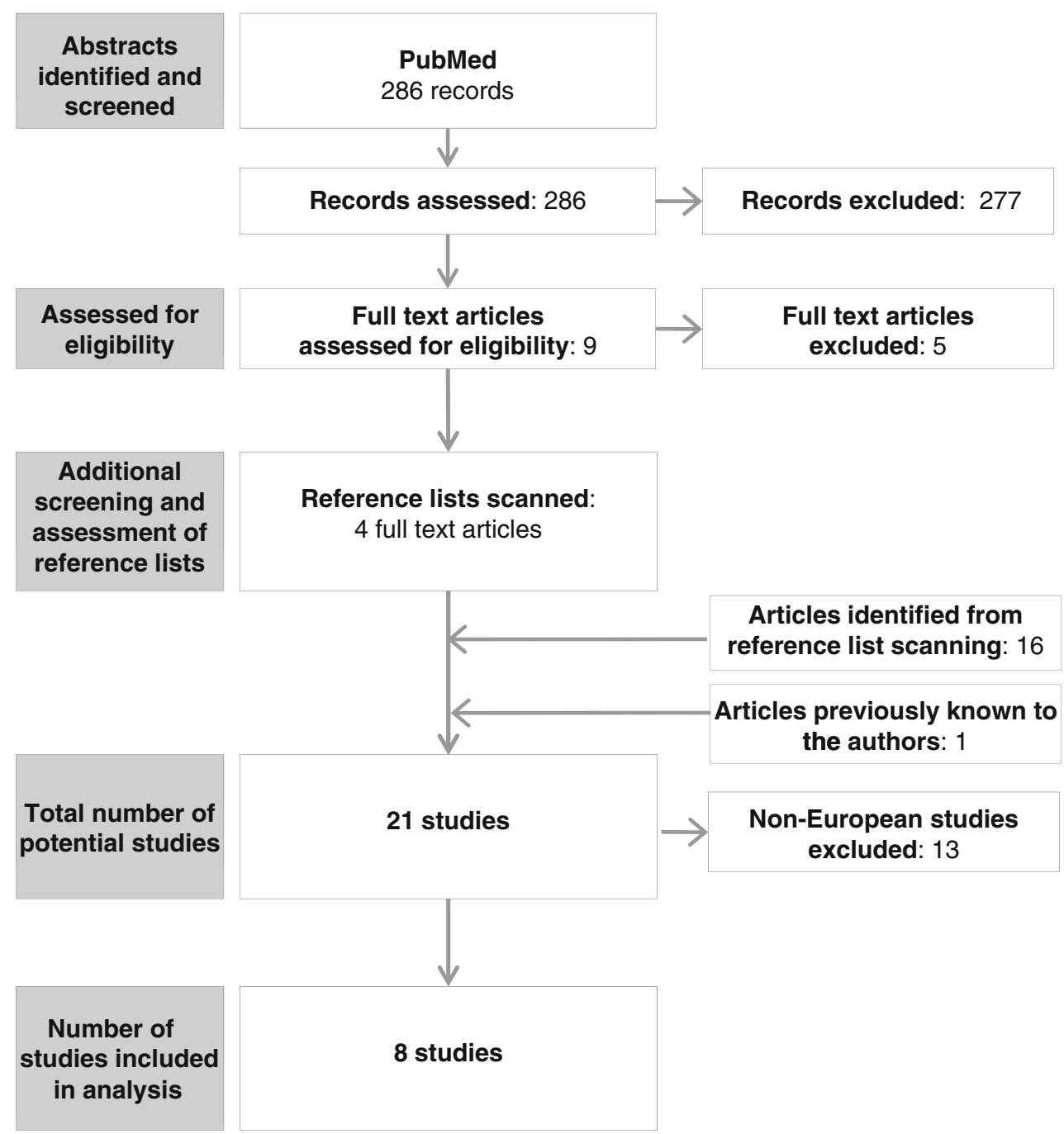

with an average of $€ 359$. In general, the cost of transfusing a second unit was slightly less expensive than the first because blood grouping, Kell typing, and cross-matching of the patient only need to be performed before the initial transfusion.

Impact of baseline $\mathrm{Hb}$ level on cost The risk difference in transfusion rates (identified by systematic review of clinical studies) was multiplied by the midpoint of the range of cost of transfusion (identified by systematic review of economic studies). Overall, the cost savings of initiating treatment with $\mathrm{DA}$ at higher versus lower $\mathrm{Hb}$ levels ranged from $€ 503$ to $€ 2,226$ ( 2 units transfused) and $€ 880$ to $€ 3,895$ (3.5 units transfused) for every ten patients (Table 4). Decrease in transfusion costs could offset the increase in DA costs.

\section{Discussion}

To the best of our knowledge, the present study is the first to examine the impact of $\mathrm{Hb}$ level at DA initiation on the cost of treating chemotherapy-induced anemia. The findings suggest that $\mathrm{RBC}$ transfusion incidence decreases with higher $\mathrm{Hb}$ levels at the time of DA initiation and that a reduction in transfusion rate is associated with reduced costs, although the actual cost savings varied between the studies examined. Although we would have preferred to combine the studies in a meta-analysis to provide more precise estimates, the heterogeneity of the studies in terms of their study designs and reporting of transfusion rates stratified by $\mathrm{Hb}$ level made this impossible. It should also be noted that the measurement period of transfusion rates and the analytical method used to report transfusion rates (Kaplan-Meier or raw percentages) also varied between studies. As Kaplan-Meier estimates account for dropouts from the studies, risk differences calculated from such estimates of transfusion rates are more likely to reflect a population estimate, and cost savings calculated on this basis are, therefore, more likely to reflect real-life clinical practice.

While the present study showed that early initiation of DA can lead to a reduction in the costs associated with $\mathrm{RBC}$ transfusion, there are other important potential benefits from reducing transfusion rates. For example, there are risks 
Table 2 Characteristics of the eight studies identified in the systematic review of economic studies

\begin{tabular}{|c|c|c|c|c|c|c|c|}
\hline Study & $\begin{array}{l}\text { Study } \\
\text { year }\end{array}$ & Country & Setting & Study perspective & Study design & Type of costing & $\begin{array}{l}\text { Units } \\
\text { analyzed }\end{array}$ \\
\hline Agrawal et al. 2006 [23] & 2004 & UK & Hematology/oncology & Hospital & Prospective & Bottom-up & 2 units/1 unit \\
\hline Glenngård et al. 2005 [24] & 2002 & Sweden & General & Societal & Prospective & Bottom-up & 2 units/1 unit \\
\hline Brilhante et al. 2008 [32] & 2007 & Portugal & Hemato-oncology & Hospital & Prospective & Bottom-up & 2 units/1 unit \\
\hline Darba et al. 2009 [33] & $2002-2007$ & Spain & Review & Review & Review & Review & 1 unit \\
\hline $\begin{array}{l}\text { Hadjianastassiou } \\
\text { et al. } 2002 \text { [34] }\end{array}$ & 1998-1999 & UK & Surgery & Hospital & Retrospective & Bottom-up & 2 units/1 unit \\
\hline Kanavos et al. 2006 [35] & 2004 & Greece & General & Societal & Prospective & Bottom-up & 1 unit \\
\hline Norum and Moen 2008 [36] & 2005 & Norway & Oncology & Payer & Retrospective & Top-down & 1 unit \\
\hline Varney and Guest 2003 [37] & $2000-2001$ & UK & General & Healthcare provider & Retrospective & Top-down & 1 unit \\
\hline Shander 2010 & 2008 & $\begin{array}{l}\text { Switzerland } \\
\text { and Austria }\end{array}$ & Surgery & Hospital & Retrospective & Top-down & 1 unit \\
\hline
\end{tabular}

associated with blood transfusions [1], and blood used for transfusion is also a scarce resource that must be managed efficiently. Thus, a reduction in transfusions may improve the efficient allocation of scarce resources. Furthermore, studies have shown that patients report a strong desire to avoid transfusions [42]. While such outcomes are beyond the scope of the present study, this preference can be measured using "willingness-to-pay" (WTP) analysis and can be included in the calculation of cost savings. The purpose of WTP measurements is to ascertain individual's maximum WTP for some - usually nonmarketed — good through hypothetical survey questions [43]. Per the recommendation of clinical guidelines, not only $\mathrm{Hb}$ levels but also patient symptoms and circumstances should be considered when deciding on the most appropriate treatment.

While effort should be made to reduce transfusion burden, use of ESA should follow current clinical guideline and label recommendations. Some years ago, several clinical studies and meta-analyses suggested that ESAs may reduce survival or increase disease progression [44-47]. More recent studies and meta-analyses, however, have found no negative impact upon survival $[32,48,49]$. Overall consensus has been that, when used in accordance with the prescribing information, ESA therapy is well tolerated, does not negatively affect survival, and provides important clinical benefits for patients with CIA by reducing the need for RBC transfusions and exposure to associated risks [6-11].

Previously published cost-effectiveness analyses of ESAs and RBC transfusions have generally been conducted on the basis that ESAs are an alternative to RBC transfusion, and have given conflicting results [50-52]. For example, Borget et al. [52] and Borg et al. [51] both showed that use of an ESA was cost-effective compared with RBC transfusion, while Klarenbach et al. found that ESA use was not [50]. The validity of these studies in real-life practice is, however, limited as guidelines state that ESAs and transfusions are complementary, rather than mutually exclusive, in the management of chemotherapy-induced anemia [6].

Costs of transfusion varied between countries and also from study to study, depending on the cost derivers included in the analyses and the initial economic perspective taken. While all direct labor and material costs incurred during the three main phases of the transfusion process (collection from the donor, preparation of the blood by running the
Table 32010 adjusted cost of 1 unit of red blood cell transfusion in Europe

NOK Norwegian Krone, SEK Swedish Krona

\begin{tabular}{llll}
\hline Study & $\begin{array}{l}\text { Cost of transfusion } \\
\text { (reported year) }\end{array}$ & $\begin{array}{l}\text { 2010 values in } \\
\text { original currencies }\end{array}$ & $\begin{array}{l}\text { Adjusted 2010 } \\
\text { values (€) }\end{array}$ \\
\hline Agrawal et al. 2006 [23] & $£ 402(2005)$ & $£ 460$ & $€ 537$ \\
Glenngård et al. 2005 [24] & SEK2,243 (2003) €249 & SEK2,486 & $€ 261$ \\
Brilhante et al. 2008 [32] & $€ 349(2007)$ & $€ 357$ & $€ 357$ \\
Darba et al. 2009 [33] & $€ 350(2007)$ & $€ 370$ & $€ 370$ \\
Hadjianastassiou et al. 2002 [34] & $£ 90(1999)$ & $£ 112$ & $€ 130$ \\
Kanavos et al. 2006 [35] & $€ 355(2004)$ & $€ 433$ & $€ 433$ \\
Norum and Moen 2008 [36] & NOK1,960(2006) €240 & NOK2,157 & $€ 269$ \\
Varney and Guest 2003 [37] & $£ 235(2001)$ & $£ 286$ & $€ 333$ \\
Shander 2010 & $\$ 611.44(2008)$ & $\$ 613$ & $€ 483$ \\
Average cost & $\$ 522.45$ & $\$ 535$ & $€ 421$ \\
\hline
\end{tabular}


necessary tests for safety, and transfusion to the recipient) should have been considered when reporting costs, other cost derivers are more dependent on the perspective taken.

The cost of DA treatment has been estimated at $€ 2,094$ in Belgium [53] and ranged from $€ 1,659$ to $€ 2,378$ across different European countries [54]. Considering differences in the length of treatment (12-16 weeks in clinical trials and 6 weeks in DA cost analyses), the potential cost savings of up to $€ 3,895$ for every ten patients demonstrated in the present study could be used to treat approximately one additional patient with DA. Decrease in transfusion costs could offset the increase in DA costs.

Limitations of the present study include the potential for publication selection bias arising from the use of a single publication database (PubMed). For instance, retrieved articles are highly dependent on the search strategy used, and use of multiple sources may, therefore, have reduced this effect [55]. The review of clinical studies found a trend in transfusion reduction related to $\mathrm{Hb}$ level at DA initiation, although it should be noted there were differences in baseline patient characteristics, lengths of the studies, and analytical techniques used to report transfusion incidence. In addition, it was assumed that the cost of RBC transfusion was constant for the first and subsequent units. The costs for the second unit of transfused blood, however, were found in some of the cited studies to be slightly less expensive than the first unit. The calculated cost savings reported here may, therefore, slightly overestimate the actual cost savings in clinical practice.

In conclusion, the findings of the clinical systematic review showed that transfusion incidence increases when DA is initiated at lower versus higher Hb levels. The cost of transfusion was found to vary from country to country and was dependent on the cost items included (e.g., direct and indirect costs). Overall, this study shows that the $\mathrm{Hb}$ level at DA initiation has a cost implication in the treatment of chemotherapy-induced anemia: the lower the Hb level, the greater the number of transfusions and the larger the overall cost of treatment. In patients for whom DA treatment is appropriate, treatment should, therefore, be initiated as early as possible within guideline-defined $\mathrm{Hb}$ levels, to reduce the need for transfusion and to decrease the overall cost of treatment. Clinical circumstances and symptoms of the patient should be considered while deciding on the most appropriate treatment of CIA.

Acknowledgments The authors would like to thank Daniel Booth (Bioscript Stirling Ltd) for providing editorial support, funded by Amgen.

Disclosures Melike Deger has been an employee of Amgen Europe $\mathrm{GmbH}$ at the time of the study. Lucie Kutikova is an employee of Amgen Europe GmbH. Wolfgang Eisterer and Sam Salek declare no conflict of interest. 
Open Access This article is distributed under the terms of the Creative Commons Attribution Noncommercial License which permits any noncommercial use, distribution, and reproduction in any medium, provided the original author(s) and the source are credited.

\section{References}

1. Ludwig H, Fritz E (1998) Anemia in cancer patients. Semin Oncol 25(3 Suppl 7):2-6

2. Caro JJ, Salas M, Ward A, Goss G (2001) Anemia as an independent prognostic factor for survival in patients with cancer: a systemic, quantitative review. Cancer 91:2214-2221

3. Cella D (1997) The Functional Assessment of Cancer TherapyAnemia (FACT-An) Scale: a new tool for the assessment of outcomes in cancer anemia and fatigue. Semin Hematol 34(3 Suppl 2):13-19

4. Merli F, Bertini M, Luminari S, Mozzana R, Bertè R, Trottini M et al (2004) Quality of life assessment in elderly patients with aggressive non-Hodgkin's lymphoma treated with anthracyclinecontaining regimens. Report of a prospective study by the Intergruppo Italiano Linfomi. Haematologica 89:973-978

5. Surgenor DM, Wallace EL, Hale SG, Gilpatrick MW (1988) Changing patterns of blood transfusions in four sets of United States hospitals, 1980 to 1985 . Transfusion 28:513-518

6. Aapro MS, Link H (2008) September 2007 update on EORTC guidelines and anemia management with erythropoiesis-stimulating agents. Oncologist 13(Suppl 3):33-36

7. Schrijvers D, De Samblanx H, Roila F (2010) Erythropoiesisstimulating agents in the treatment of anaemia in cancer patients: ESMO Clinical Practice Guidelines for use. Ann Oncol 21(Suppl 5):v244-v247

8. Rizzo JD, Somerfield MR, Hagerty KL, Seidenfeld J, Bohlius J, Bennett CL et al (2008) Use of epoetin and darbepoetin in patients with cancer: 2007 American Society of Clinical Oncology/American Society of Hematology clinical practice guideline update. J Clin Oncol 26:132-149

9. Janssen-Cilag Ltd (2010) Eprex 2000, 4000 and $10000 \mathrm{IU} / \mathrm{ml}$ solution for injection in pre-filled syringe. Summary of Product Characteristics. Janssen-Cilag Ltd, High Wycombe

10. Roche Products Ltd (2011) Neorecormon solution for injection in pre-filled syringe. Summary of Product Characteristics. Roche Registration Ltd, Welwyn Garden City

11. Amgen Ltd (2011) Aranesp PFS. Summary of product characteristics. Amgen Europe BV, Breda

12. Carson JL, Grossman BJ, Kleinman S, Tinmouth AT, Marques MB et al. (2012) Red blood cell transfusion: a clinical practice guideline from the AABB. Ann Intern Med 157:49-58

13. Vansteenkiste J, Tomita D, Rossi G, Pirker R (2004) Darbepoetin alfa in lung cancer patients on chemotherapy: a retrospective comparison of outcomes in patients with mild versus moderateto-severe anaemia at baseline. Support Care Cancer 12:253-262

14. Egrie JC, Browne JK (2001) Development and characterization of novel erythropoiesis stimulating protein (NESP). Nephrol Dial Transplant 16(Suppl 3):3-13

15. Vansteenkiste J, Wauters I (2007) Darbepoetin alfa for chemotherapy-induced anemia: evolution to extended dosing intervals. Expert Rev Anticancer Ther 7:1347-1355

16. EL.STAT (2011) Pireas: Hellenic Statistical Authority. http:// www.statistics.gr. Accessed 1 Aug 2011

17. Statistics Spain (2011) Madrid: Instituo Nacional de Estadística. http://www.ine.es/. Accessed 1 Aug 2011

18. Statistics Portugal (2011) Lisbon: Instituo Nacional de Estatística. http://www.ine.pt/. Accessed 1 Aug 2011
19. Statistics Norway (2011) Oslo: Statistisk sentralbyrå; 2011. http:// www.ssb.no/. Accessed 1 August 2011

20. Statistics Sweden (2011) Stockholm: Statistsika centralbyrån; 2011. http://www.scb.se/. Accessed 1 Aug 2011

21. UK National Statistics (2011) Newport: Office of National Statistics; 2011. http://www.statistics.gov.uk. Accessed 1 Aug 2011

22. Statistics Switzerland (2012) Neuchatel: Statistik Schweiz; 2012. http://www.bfs.admin.ch/. Accessed 16 May 2012

23. Statistics Austria (2012) Wien: Statistics Austria; 2012. http:// www.statistik.at/. Accessed 16 May 2012

24. Euro foreign exchange reference rates (2011) Frankfurt: European Central Bank; 2011. http://www.ecb.int/stats/exchange/eurofxref/ html/index.en.html. Accessed 6 Dec 2011

25. Eisterer W, Hussl C, Erb H, Haslbauer F, Sormann S, Braun S et al (2011) RETRA: evaluating the transfusion rate with darbepoetin alfa 500 microg every 3 weeks in anaemic cancer patients receiving chemotherapy. Curr Med Res Opin 27:355-363

26. Agrawal S, Davidson N, Walker M, Gibson S, Lim C, Morgan CL et al (2006) Assessing the total costs of blood delivery to hospital oncology and haematology patients. Curr Med Res Opin 22:19031909

27. Glenngård AH, Persson U, Söderman C (2005) Costs associated with blood transfusions in Sweden: the societal cost of autologous, allogeneic and perioperative RBC transfusion. Transfus Med 15:295-306

28. Gabrilove JL, Perez EA, Tomita DK, Rossi G, Cleeland CS (2007) Assessing symptom burden using the M. D. Anderson symptom inventory in patients with chemotherapy-induced anemia: results of a multicenter, open-label study (SURPASS) of patients treated with darbepoetin-alpha at a dose of 200 microg every 2 weeks. Cancer 110:1629-1640

29. Boccia R, Malik IA, Raja V, Kahanic S, Liu R, Lillie T et al (2006) Darbepoetin alfa administered every three weeks is effective for the treatment of chemotherapy-induced anemia. Oncologist 11:409-417

30. Charu V, Saidman B, Ben-Jacob A, Justice GR, Maniam AS, Tomita D et al (2007) A randomized, open-label, multicenter trial of immediate versus delayed intervention with darbepoetin alfa for chemotherapy-induced anemia. Oncologist 12:1253-1263

31. Mel JR, Salar A, Rodriguez CA, Alegre A, González A, Cassinello $\mathrm{J}$ et al (2008) A prospective observational study of the effectiveness, safety, and effect on fatigue of darbepoetin alfa for the treatment of chemotherapy-induced anaemia. Curr Med Res Opin 24:2931-2942

32. Ludwig H, Crawford J, Osterborg A, Vansteenkiste J, Henry DH, Fleishman A et al (2009) Pooled analysis of individual patientlevel data from all randomized, double-blind, placebo-controlled trials of darbepoetin alfa in the treatment of patients with chemotherapy-induced anemia. J Clin Oncol 27:2838-2847

33. Canon JL, Vansteenkiste J, Hedenus M, Gascon P, Bokemeyer C, Ludwig $\mathrm{H}$ et al. (2011) Transfusion risk in cancer patients with chemotherapy-induced anemia when initiating darbepoetin alfa therapy at a baseline hemoglobin level of $<9 \mathrm{~g} / \mathrm{dL}$ versus 9 to $<10 \mathrm{~g} / \mathrm{dL}$ versus $\geq 10 \mathrm{~g} / \mathrm{dL}$ : an exploratory analysis of a phase 3 trial. Med Oncol. doi:10.1007/s12032-011-0103-x

34. Malik I, Kahanic S, Liu R, Tchekmedyian S, Tomita D, Lillie T et al (2006) Effectiveness of darbepoetin alfa administered every 3 weeks on clinical outcomes in patients with gastrointestinal cancer and chemotherapy-induced anemia. Poster presented at the ASCO Gastrointestinal Cancers Symposium, San Francisco, CA; Abstract 382

35. Brilhante D, Macedo A, Santos A (2008) Estimating the microcosts of blood transfusion for hemato-oncological patients. Acta Med Port 21:575-580

36. Darba J, Restovic G, Arocho R (2009) Blood transfusion costs in Spain. Review of the literature 2002-2007. PharmacoEconomics Span Res Art 6:44-54 
37. Hadjianastassiou VG, Virich G, Lennox IA (2002) Use of the blood transfusion service in total knee replacement arthroplasty. The cost implications. Knee 9:145-148

38. Kanavos P, Yfantopoulos J, Vandoros C, Politis C (2006) The economics of blood: gift of life or a commodity? Int J Technol Assess Health Care 22:338-343

39. Norum J, Moen MA (2008) Practice and costs of red blood cell (RBC) transfusion in an oncological unit. Anticancer Res 28:459464

40. Varney SJ, Guest JF (2003) The annual cost of blood transfusions in the UK. Transfus Med 13:205-218

41. Shander A, Hofmann A, Ozawa S, Theusinger OM, Gombotz H, Spahn DR (2010) Activity-based costs of blood transfusions in surgical patients at four hospitals. Transfusion 50:753765

42. Demetri GD (2001) Anaemia and its functional consequences in cancer patients: current challenges in management and prospects for improving therapy. Br J Cancer 84(Suppl 1):31-37

43. Berger ML, Bingefors K, Hedblom EC, Pashos CL, Torrance GW (2003) Health care cost, quality, and outcomes: ISPOR book of terms. ISPOR, Lawrenceville

44. Bohlius J, Schmidlin K, Brillant C, Schwarzer G, Trelle S, Seidenfeld $\mathrm{J}$ et al (2009) Erythropoietin or darbepoetin for patients with cancer: meta-analysis based on individual patient data. Cochrane Database Syst Rev 3:CD007303

45. Bohlius J, Wilson J, Seidenfeld J et al (2006) Erythropoietin or darbepoetin for patients with cancer. Cochrane Database Syst Rev 3:CD003407

46. Bennett CL, Silver SM, Djulbegovic B et al (2008) Venous thromboembolism and mortality associated with recombinant erythropoietin and darbepoetin administration for the treatment of cancerassociated anemia. JAMA 299:914-924
47. Tonelli M, Hemmelgarn B, Reiman T et al (2009) Benefits and harms of erythropoiesis-stimulating agents for anemia related to cancer: a meta-analysis. CMAJ 180:E62-E71

48. Glaspy J, Crawford J, Vansteenkiste J et al (2010) Erythropoiesisstimulating agents in oncology: a study-level meta-analysis of survival and other safety outcomes. Br J Cancer 102:301-315

49. Vansteenkiste J, Glaspy J, Henry D et al (2012) Benefits and risks of using erythropoiesis-stimulating agents (ESAs) in lung cancer patients: study-level and patient-level meta-analyses. Lung Cancer 76:478-485

50. Klarenbach S, Manns B, Reiman T, Reaume MN, Lee H, Lloyd A et al (2010) Economic evaluation of erythropoiesis-stimulating agents for anemia related to cancer. Cancer 116:3224-3232

51. Borg S, Glenngård AH, Osterborg A, Persson U (2008) The costeffectiveness of treatment with erythropoietin compared to red blood cell transfusions for patients with chemotherapy induced anaemia: a Markov model. Acta Oncol 47:1009-1017

52. Borget I, Tilleul P, Baud M, Joly AC, Daguenel A, Chouaid C (2006) Routine once-weekly darbepoetin alfa administration is cost-effective in lung cancer patients with chemotherapy-induced anemia: a Markov analysis. Lung Cancer 51:369-376

53. Spaepen E, Demarteau N, Van Belle S, Annemans L (2008) Health economic evaluation of treating anemia in cancer patients receiving chemotherapy: a study in Belgian hospitals. Oncologist 13:596-607

54. Duran A, Spaepen E, Lamotte M, Walter E, Lucioni C, Pinheiro B et al (2011) Cost analysis of anemia treatment with erythropoiesesstimulating agents (ESAs) in patients with cancer receiving chemotherapy: a multi-country approach. Poster presented at ISPOR 16th Annual International Meeting, Baltimore, MD; Abstract PSY10

55. Sutton AJ, Abrams KR, Jones DR, Sheldon TA, Song F (1998) Systematic reviews of trials and other studies. Health Technol Assess 2:1-276 